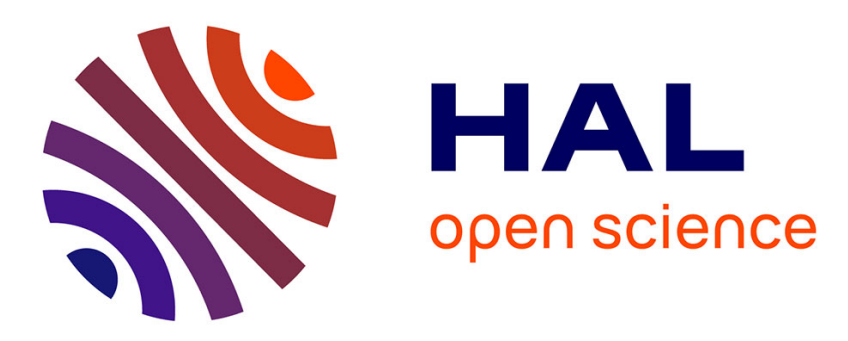

\title{
Changes in the Output Euler Equation and Asset Markets Participation
}

\author{
Florin Bilbiie, Roland Straub
}

\section{To cite this version:}

Florin Bilbiie, Roland Straub. Changes in the Output Euler Equation and Asset Markets Participation. Journal of Economic Dynamics and Control, 2012, 36 (11), pp.1659-1672. 10.1016/j.jedc.2012.03.018 . hal-00680647

\section{HAL Id: hal-00680647 \\ https://hal-paris1.archives-ouvertes.fr/hal-00680647}

Submitted on 27 Mar 2012

HAL is a multi-disciplinary open access archive for the deposit and dissemination of scientific research documents, whether they are published or not. The documents may come from teaching and research institutions in France or abroad, or from public or private research centers.
L'archive ouverte pluridisciplinaire HAL, est destinée au dépôt et à la diffusion de documents scientifiques de niveau recherche, publiés ou non, émanant des établissements d'enseignement et de recherche français ou étrangers, des laboratoires publics ou privés. 


\title{
Changes in the Output Euler Equation and Asset Markets Participation
}

\author{
Florin O. BILBIIE* and Roland Straub ${ }^{\star}$ \\ *Paris School of Economics, Univ. Paris I Panthéon-Sorbonne and CEPR \\ $\diamond$ European Central Bank
}

\begin{abstract}
Recent estimates of the output Euler equation for the United States indicate that the elasticity of aggregate demand to interest rates is not significantly different from zero. We first argue that this result may hide a structural break: the estimated elasticity is a convolution of two coefficients with opposite signs across the samples 1965-1979 and 1982-2003. The sign of the coefficient in the earlier sample is inconsistent with standard economic theory and intuition. We outline a model with limited asset markets participation that can generate this change in sign when asset market participation changes from low to high, and provide institutional evidence for such a change in the United States in the late 70s and early 80s.

Keywords: IS curve; Euler equation for output; limited asset markets participation; aggregate demand; rule-of-thumb consumers.

JEL codes: E32; G11; E44; E31; E52; E58.
\end{abstract}

\footnotetext{
Addresses: Bilbiie: Centre d'Economie de la Sorbonne, 106-112 Boulevard de l'Hopital, 75013 Paris; florin.bilbiie "at" parisschoolofeconomics.eu; http://florin.bilbiie.googlepages.com; Straub: roland.straub@ecb.int.

We are indebted for comments or discussions to Roberto Perotti, Giancarlo Corsetti, Jordi Galí, Andrew Scott, Michael Woodford, Roger Farmer, Kosuke Aoki, Mike Artis, Gianluca Benigno, Paul Bergin, Giuseppe Bertola, Fabrice Collard, Mike Haliassos, Stephanie Schmitt-Grohe, Fabio Ghironi, Nobu Kiyotaki, David Lopez-Salido, Albert Marcet, Alex Michaelides, Tommaso Monacelli, John Muellbauer, Gernot Mueller, Kris Nimark, Fabrizio Perri, Jon Skinner and Jaume Ventura. We thank Jeffrey Fuhrer and Liz Walat for providing us with the data and Bergljot Barkbu for help with codes. Participants at the CEPR's European Summer Symposium in Macroeconomics in Tarragona, and seminars at Harvard, London Business School, London School of Economics, CREI-Universitat Pompeu Fabra, Nuffield College, Oxford, European University Institute, Birkbeck, IGIER-Bocconi and DOFIN provided valuable comments. Bilbiie thanks Banque de France for financial support through the eponymous Chair at the Paris School of Economics. The views expressed in this paper are those of the authors and do not necessarily reflect those of Banque de France and European Central Bank, or their policies.
} 


\section{Introduction}

At the core of microfounded, optimization-based macroeconomic models lies an aggregate Euler equation relating aggregate output to real interest rates: the Output Euler Equation (OEE in short). This equation (also known as 'the intertemporal IS curve') takes, under a variety of preference specifications, the simple form:

$$
y_{t}=E_{t} y_{t+1}+d\left[r_{t}-E_{t} \pi_{t+1}\right]+\eta_{t},
$$

where $y_{t}$ is output, $r_{t}$ nominal interest rates, $E_{t} \pi_{t+1}$ expected inflation, and $\eta_{t}$ an 'aggregate demand shock'; it origins in the intertemporal Euler equation describing the asset-holding/investment decision of households combined with the aggregate resource constraint of the economy. Correspondingly, the coefficient $d$ (the slope of the OEE) is the negative of the 'aggregate elasticity of intertemporal substitution', or AEIS for short. ${ }^{1}$ Standard theory predicts that the coefficient $d$ is negative, because an increase in interest rates leads the representative agent to substitute consumption (output) today for consumption (output) tomorrow. This mechanism implies a strong role for macroeconomic policy to influence the economy: monetary policy can affect aggregate demand by manipulating nominal interest rates, while fiscal policy can induce intertemporal substitution in labor supply by changing the temporal path of tax rates on labor income. The OEE is a central building block of virtually every model used for policy analysis at central banks or financial institutions, no matter how many additional features such models include. ${ }^{2}$ Smaller-scale models (see e.g. Woodford, 2003) featuring in addition imperfect price adjustment (and hence a Phillips curve, or inflation dynamics equation) and a Taylor-type policy rule relating nominal interest rates to endogenous variables such as inflation and output capture the essence of these larger-scale models.

This paper undertakes an empirical study of the OEE with a particular focus on the stability of one parameter: AEIS. In a nutshell, while existing studies reviewed in detail below consistently find this parameter to be not significantly different from zero (hence pointing to little if any evidence of intertemporal substitution), our paper argues that this finding may be due to a structural break in this coefficient: namely, a convolution of a positive $d$ in the pre-1979 sample and a negative one in the later sample.

Many empirical studies have focused on the performance of single equations in describing the dynamics of the data. To give just some prominent examples, Sbordone (2006) and Galí and Gertler (1999) demonstrate that the New Keynesian Phillips curve, which relates inflation to its expected value and a measure of real activity, is able to mimic the dynamics of inflation in the United States; yet others, starting with Taylor (1999) and Clarida, Galí, and Gertler (2000) provided empirical evidence that simple interest rate rules relating nominal interest rates to inflation and a measure of real activity are successful in reproducing the conduct of monetary policy.

\footnotetext{
${ }^{1}$ In a benchmark model with CRRA utility the AEIS equals the inverse of the coefficient of relative risk aversion in consumption.

${ }^{2}$ A growing number of papers demonstrates the ability of medium-scale dynamic stochastic general equilibrium models to reproduce the unconditional and conditional moments in macroeconomic data; see for example Christiano Eichenbaum and Evans (2005), Smets and Wouters (2003) and Peersman and Straub (2006).
} 
Although receiving an equal weight within optimization-based macroeconomic theory, the OEE seems to be less of an empirical success story than its companions. ${ }^{3}$ One of the first papers providing a comprehensive empirical analysis of the OEE is Fuhrer and Rudebusch (2004). They find that the estimated AEIS is not significantly different from zero, ${ }^{4}$ a result which is confirmed by Fuhrer and Olivei (2004). Estrella and Fuhrer (2003) also estimated an OEE and wrote that 'results [...] are disappointing'. These results pose a serious challenge for standard theory relying on aggregate demand logic, which predicts that AEIS is unambiguously positive ( $d$ unambiguously negative).

In a broader sense, this challenge is not new: many studies have used consumption data and showed that the consumption Euler equation fails to hold at the aggregate level. ${ }^{5}$ Most recently, Yogo (2004) undertook a comprehensive empirical study for eleven countries and concluded that there is virtually no evidence for intertemporal substitution. A plethora of papers (see e.g. Campbell, 2003) have reached the same conclusion ever since, two decades ago, Hall (1988) concluded that 'there is no intertemporal substitution in consumption'. Relatedly, Canzoneri, Cumby and Diba (2007) have recently argued that the interest rate implied by consumption Euler equations calculated for a variety of utility functions is negatively correlated with the federal funds rate. ${ }^{6}$

In this paper, we propose a solution to this empirical puzzle, solution which is made of three ingredients. First, we argue that the zero AEIS estimated over the whole sample comes from a convolution of a negative and a positive AEIS in two subsamples: we find evidence for such a structural break in AEIS between the pre-1979 and the post-1982 samples. ${ }^{7}$ However, this creates an extra puzzle for standard theory, which predicts that the AEIS is positive, i.e. aggregate demand is negatively related to real interest rates. Therefore, we next show that a model with limited asset markets participation can explain this shift by a change in the share of households participating in asset markets, from low to high: at low enough participation rates, the AEIS is indeed negative. Lastly, we provide institutional evidence consistent with our hypothesis: profound changes took place in U.S. financial markets - that led to more widespread asset holding - around the same date when the AEIS changed sign.

Empirically, our first finding of an AEIS with the 'wrong' sign in the first subsample is rather surprising at first sight but in fact echoes estimates already present in existing literature. The estimates presented by Hansen and Singleton

\footnotetext{
${ }^{3}$ McCallum and Nelson (1998) and Rotemberg and Woodford (1998) were among the first to estimate an Euler equation for output in the context of small-scale, optimization based macroeconomic models.

${ }^{4}$ Fuhrer and Rudebusch (2004) used both generalized method of moments (GMM) and Maximum likelihood (ML) methods and showed that they provide disparate estimates for the significance of the forward looking component $E_{t} y_{t+1}$; the finding of no intertemporal substitution, however, is a robust one - not only to the estimation method used, but also to a wide variety of output detrending methods, real interest rate definitions and (in the GMM case) instrument sets.

${ }^{5}$ See e.g. Hall (1988), Campbell and Mankiw (1989), Hansen and Singleton (1996), VissingJorgensen (2002) and Yogo (2004).

${ }^{6}$ Moreover, they show that the spread between the two is systematically linked to measures of the monetary stance.

${ }^{7}$ In particular, we present the results of a GMM estimation for two separate subsamples and determine the timing of the structural break endogenously using recursive estimation and the Wald test for GMM estimators proposed by Andrews (1993).
} 
(1996) using data before 1986 consistently have the 'wrong' sign. Some of Hall's (1988, p. 353) estimates also share this feature, ${ }^{8}$ as do Campbell's (2003). Finally, Estrella and Fuhrer (2003) find a structural break in the AEIS in the same period as ours (1979-1982), although they do not report the values of the estimates.

Theoretically, our proposed solution to the puzzle based on limited asset markets participation is related to already proposed solutions to the zero-elasticity puzzle in the consumption literature. In particular, using micro data and taking into account household heterogeneity with respect to their asset holding status Vissing-Jorgensen (2002) showed that significant evidence for intertemporal substitution is obtained once one excludes from the sample households who hold no assets and therefore have no means of substituting intertemporally, or bluntly, no Euler equation. ${ }^{9}$ This paper is related to that approach insofar as it takes into account micro heterogeneity related to asset markets participation. The important differences are as follows. First, we embed this assumption into a macro model and derive its aggregate, macro implications; in that sense, in can be viewed as a macro counterpart to Vissing-Jorgensen's study. This is in our view worthwhile pursuing because the OEE is used in macroeconomic models for policy analysis. Second, we show that this approach can address not only the puzzle of 'zero intertemporal substitution' at the aggregate level, but also the change in the (sign of the) AEIS documented empirically.

Furthermore, we provide a cautionary note on drawing inference about the fraction of non-asset holding (or 'rule-of-thumb') population based on the estimation of their share of total income when using aggregate data. This is the route taken by Campbell and Mankiw (1989), Fuhrer (2000) and Galí, Lopez-Salido and Valles (2007). We argue that equating the fraction of rule-of-thumb consumers with their share in total income is subject to a potentially sizeable bias insofar as there is income heterogeneity between asset holders and non-asset holders: if non-asset holders (rule-of-thumb consumers) merely consume their wage income (whereas asset holders receive asset income), the elasticity of their consumption to total income will crucially depend on aggregate labor supply elasticity and not only on their weight in the population. We outline an example and quantify the magnitude of this potential bias.

Finally, it is worth mentioning that the reason why we focus on the output (as opposed to consumption) Euler equation is not only its relevance for macroeconomic models, but also to avoid issues raised by non-separability of consumption and leisure in the utility function explored by Basu and Kimball (2006) and Galí et al. (2007) and reviewed below. In fact, we show that our OEE can occur under nonseparable preferences, but only limited asset markets participation can generate the change in sign of the AEIS that we document empirically.

The remainder of the paper is organized as follows. In section 2, we present our empirical evidence, using structural break tests and GMM estimation that the AEIS switched sign in the late 1970s, early 1980s. In Section 3, we show that a model with limited asset market participation can explain this empirical finding by

${ }^{8}$ Hall (1988) rejects such estimates as implausible since they would imply non-concave utility in a representative-agent framework.

${ }^{9}$ See also and Brav, Constantinides and Geczy (2002) for a related study using limited participation to address asset pricing puzzles. Guvenen (2006) studies a calibrated business cycle model with limited stock parket participation and preference heterogeneity; we discuss this in some detail in Section 3. 
an increase in the share of asset market participants. In section 4 we put together some background institutional evidence suggesting that the U.S. economy in the mid 1960's and 1970s was indeed characterized by lower asset market participation as compared to the post-1980 period. Section 5 provides some concluding remarks.

\section{The estimated AEIS: a convolution of positive and negative values?}

In this section, we assess the structural stability of the OEE over the post-1965 period. ${ }^{10}$ To that end, we follow Fuhrer and Rudebusch (2004) (see also Fuhrer and Olivei, 2005) and use the same data set, variables, and estimation method. ${ }^{11}$ We present evidence that a significant change in the AEIS occurred in the 1979-1982 period. This evidence comes from a few sources: (i) estimates over the subsamples 1965-1979 and 1982-2003; (ii) recursive estimations; (iii) test for structural change.

We estimate by the Generalized Method of Moments (GMM) the following 'expanded' OEE: ${ }^{12}$

$$
y_{t}=a_{0}+a_{1} y_{t-1}+a_{2} y_{t-2}+b E_{t} y_{t+1}+d E_{t-\tau}\left[\frac{1}{k} \sum_{j=0}^{k-1}\left(r_{t+j+m}-\pi_{t+j+m+1}\right)\right]+\eta_{t} \text {. }
$$

This form generalizes the simple Euler equation over four dimensions discussed in detail in Fuhrer and Rudebusch (2004): influence of lagged terms of the output gap, flexible timing of expectation formation $(\tau),{ }^{13}$ influence of past real rates (captured by $m$ ), and flexible interest rate duration (governed by $k$ ). In the first set of estimations, we perform robustness checks by using different methods to detrend output: (i) a Hodrick-Prescott filter; (ii) a segmented linear trend with one break; (iii) a segmented trend with two breaks; (iv) a quadratic trend; (v) a segmented quadratic trend; (vi) the 'potential output' measure of the Congressional Budget Office (CBO); (vi) one-sided band-pass filter (BP2). In what follows, we will focus on the (most widely used) HP filtered output gap. The variable $r_{t}$ stands for the quarterly average of the overnight federal funds rate and inflation $\pi_{t}$ is the annualized log change in the price index. ${ }^{14}$ One issue concerns the instrument set to be used for estimations: following Fuhrer and Rudebusch (2004) and Fuhrer and Olivei (2005), we use four lags of the output gap, federal funds rate and inflation. In the robustness analysis, we also use the same set of exogenous instruments: (four lags of) real defense expenditure, relative oil prices and the political party of the sitting U.S. President.

${ }^{10}$ Following Fuhrer and Rudebusch (2004), we choose 1965 as a starting date since only thereafter did the federal funds rate act as the primary instrument of monetary policy.

${ }^{11}$ We thank Jeffrey Fuhrer, Glenn Rudebusch and Liz Walat for providing us with the data.

${ }^{12}$ Fuhrer and Rudebusch (2004) also provide Monte Carlo evidence that GMM estimates are more likely to be subject to bias than maximum likelihood estimates. However, as the evidence in their paper indicates, this objection is particularly binding for estimates of the parameter $b$, i.e. the coefficient on future output. The evidence on the $d$ coefficient is at best mixed.

${ }^{13}$ For GMM estimation, this is implicitly given by the timing of instruments: e.g., $\tau=1$ when lags of the instruments are considered.

${ }^{14}$ Note that the interest rate used in the estimation is the four-quarter moving average when $k=4$. 
2.1. No endogenous persistence - the simplest version. For a first test, we perform estimations of the OEE under no endogenous persistence, i.e. setting $a_{1}=a_{2}=0, k=1, m=0$ in $(2.1)$, such that $d$ strictly corresponds to the (negative of the) theoretical AEIS:

$$
y_{t}=a_{0}+b E_{t} y_{t+1}+d\left[r_{t}-E_{t} \pi_{t+1}\right]+\eta_{t} .
$$

We estimate the equation over the two subsamples: the pre-Volcker 'Great Inflation' period, 1965:4-1979:3 and the Volcker-Greenspan period excluding the Volcker disinflation, 1983:1-2003:1. While we exclude the Volcker disinflation period for comparison with the studies performing this sample-splitting exercise for monetary policy rules, such as Clarida, Galí, Gertler (2000), when performing recursive estimation below we consider the whole sample.

The results reported in Table 1 show estimates of the coefficients with standard errors, and the $p$-value from Hansen's $J$-test. The estimates show a change in the sign of $d$ from a positive value, which is inconsistent with standard economic theory, to a negative value predicted by the standard logic. At the same time, the coefficient on expected output $b$ is almost always close to unity, as expected from theory. The estimates for $b$ are generally not significant, which is a result also obtained by Fuhrer and Rudebusch for the whole sample for the case without endogenous persistence. This is natural, given that we do not include lagged value of output among the regressors; the specification studied next allows us to obtain significant estimates for this parameter, too. Lastly, the instruments are valid as judged by the $J$-test and the results are reassuringly robust to the detrending method used, to whether contemporaneous or lagged interest rate is included and to the instrument set. ${ }^{15}$

2.2. The OEE under Endogenous Persistence. Fuhrer and Rudebusch (2004) argue that testing for the simplest version of the OEE might be marked by misspecification, due to the absence of other potentially relevant dynamic effects such as those embodied in (2.1) and described before. They indeed find that lagged terms of output are significant economically and statistically ${ }^{16}$, and the coefficient on expected output is significantly lower than one. However, the $d$ parameter is not significantly different from zero for most estimations for the whole sample, no matter the timing and duration of interest rate used, the output detrending method, the instrument set or the estimation method employed. Hence, we also estimate the richer version of the OEE (2.1) by $\mathrm{GMM}^{17}$ and try to assess the stability of this parameter. Results are reported in Table 2, where for the sake of brevity we only deal with HP-filtered output and endogenous instruments. The coefficient $d$ changes again sign from positive and significant to negative and (statistically) significant.

\footnotetext{
${ }^{15}$ Not all permutations are reported in the table, but this result carries over to most of the possible combinations of interest rate timing, output detrending method and instrument set used. Note that the $J$-test test is distributed with 9 degrees of freedom (12 when using exogenous instruments) since we only estimate three parameters.

${ }^{16}$ This echoes results obtained by Fuhrer (2000), who proposes a model based on habit formation that can explain such endogenous persistence.

${ }^{17}$ Fuhrer and Rudebusch (2004) also perform MLE estimation and show that it performs better as far as estimation of the forward-looking coefficient is concerned, but the two methods lead to similar results as far as the AEIS is concerned. We stick to the simpler GMM method for estimating the OEE; in a companion paper, we adopt a Bayesian estimation method and treat all variables as endogenous - see Bilbiie and Straub (2006).
} 
CHANGES IN THE OUTPUT EULER EQUATION AND ASSET MARKETS PARTICIPATION 7

TABLE 1: GMM estimation of the no-persistence OEE for the two sub-samples

\begin{tabular}{|c|c|c|c|c|c|}
\hline potential output & $b$ & $\mathrm{SE}(b)$ & $d$ & $\mathrm{SE}(d)$ & $J$-test $p$-val \\
\hline \multicolumn{6}{|c|}{ Pre-Volcker } \\
\hline$\overline{\mathrm{HP}}(m=0)$ & 0.85 & 0.11 & 0.30 & 0.10 & 0.59 \\
\hline $\mathrm{HP}(m=-1)$ & 1.15 & 0.09 & 0.18 & 0.09 & 0.71 \\
\hline Quadratic & 0.97 & 0.06 & 0.33 & 0.12 & 0.67 \\
\hline Segmented & 1.02 & 0.07 & 0.25 & 0.13 & 0.65 \\
\hline $\mathrm{ST} 2$ & 1.03 & 0.05 & 0.28 & 0.10 & 0.82 \\
\hline ST952 & 1.02 & 0.05 & 0.28 & 0.11 & 0.81 \\
\hline $\mathrm{CBO}$ & 1.03 & 0.05 & 0.33 & 0.12 & 0.74 \\
\hline BP2 & 1.02 & 0.05 & 0.16 & 0.04 & 0.55 \\
\hline HP, exog. instr. & 0.94 & 0.08 & 0.16 & 0.05 & 0.86 \\
\hline Quadratic, exog. instr. & 0.99 & 0.04 & 0.35 & 0.06 & 0.97 \\
\hline CBO, exog. instr. & 1.04 & 0.03 & 0.32 & 0.06 & 0.97 \\
\hline ST, exog. instr. & 0.99 & 0.05 & 0.33 & 0.06 & 0.96 \\
\hline ST952, exog. instr. & 1.15 & 0.09 & 0.17 & 0.09 & 0.71 \\
\hline \multicolumn{6}{|c|}{ Volcker-Greenspan } \\
\hline $\mathrm{HP},(m=0)$ & 1.43 & 0.10 & -0.13 & 0.04 & 0.62 \\
\hline $\mathrm{HP}(m=-1)$ & 1.36 & 0.09 & -0.11 & 0.04 & 0.50 \\
\hline Quadratic & 0.94 & 0.03 & 0.01 & 0.04 & 0.34 \\
\hline Segmented & 1.07 & 0.05 & -0.09 & 0.06 & 0.32 \\
\hline ST2 & 1.22 & 0.03 & -0.20 & 0.03 & 0.65 \\
\hline ST952 & 1.26 & 0.03 & -0.15 & 0.03 & 0.67 \\
\hline $\mathrm{CBO}$ & 1.18 & 0.03 & -0.08 & 0.04 & 0.47 \\
\hline $\mathrm{BP} 2$ & 1.10 & 0.04 & -0.02 & 0.02 & 0.25 \\
\hline HP, exog. instr. & 0.57 & 0.09 & 0.06 & 0.07 & 0.85 \\
\hline ST, exog. instr. & 1.04 & 0.04 & -0.14 & 0.04 & 0.69 \\
\hline ST952, exog. instr. & 1.05 & 0.06 & -0.12 & 0.04 & 0.72 \\
\hline
\end{tabular}

TABLE 2: GMM estimation of the augmented OEE for the two sub-samples

\begin{tabular}{lcccccc}
\hline \hline interest rate & $a_{1}+a_{2}$ & $b$ & $\mathrm{SE}(b)$ & $d$ & $\mathrm{SE}(d)$ & J-test p-val. \\
\hline \multicolumn{7}{c}{ Pre-Volcker } \\
\hline$k=4, m=0$ & 0.53 & 0.35 & 0.10 & $\mathbf{0 . 1 0}$ & 0.06 & 0.446 \\
$k=4, m=-1$ & 0.46 & 0.32 & 0.11 & $\mathbf{0 . 2 3}$ & 0.07 & 0.489 \\
$k=1, m=0$ & 0.13 & 0.89 & 0.14 & $\mathbf{0 . 1 6}$ & 0.17 & 0.572 \\
$k=1, m=-1$ & 0.58 & 0.46 & 0.08 & $\mathbf{- 0 . 0 4}$ & 0.08 & 0.476 \\
\hline \multicolumn{7}{c}{ Volcker-Greenspan } \\
\hline$k=4, m=-0$ & 0.54 & 0.53 & 0.08 & $\mathbf{- 0 . 0 1 5}$ & 0.01 & 0.158 \\
$k=4, m=-1$ & 0.53 & 0.52 & 0.07 & $\mathbf{- 0 . 0 1 4}$ & 0.01 & 0.164 \\
$k=1, m=0$ & 0.5 & 0.65 & 0.10 & $\mathbf{- 0 . 0 5 0}$ & 0.01 & 0.161 \\
$k=1, m=-1$ & 0.46 & 0.69 & 0.11 & $\mathbf{- 0 . 0 5 0}$ & 0.01 & 0.152 \\
\hline
\end{tabular}

2.3. Finding the Structural Break in the AEIS Endogenously. To further grasp the evolution over time of the estimated $d$, we perform a recursive estimation. For the remainder of the analysis we focus on the richer specification (2.1), 
using HP-filtered output gap, endogenous instruments and the interest rate corresponding to $k=4, m=-1$. In Figure 1, we report the results of 'increasing sample' estimates of $d$, i.e. estimates obtained by running the GMM estimation for an initial sample of 50 observations, and then augmenting the sample by one observation at each iteration. The results reported in Figure 1 (together with two-standard-error bands) show a sharp decrease in the coefficient from a positive significant value to a value close to zero. This decline occurs around quarter 18, which added to 50 observations used in the initial estimation suggests a break date just before 1982 .

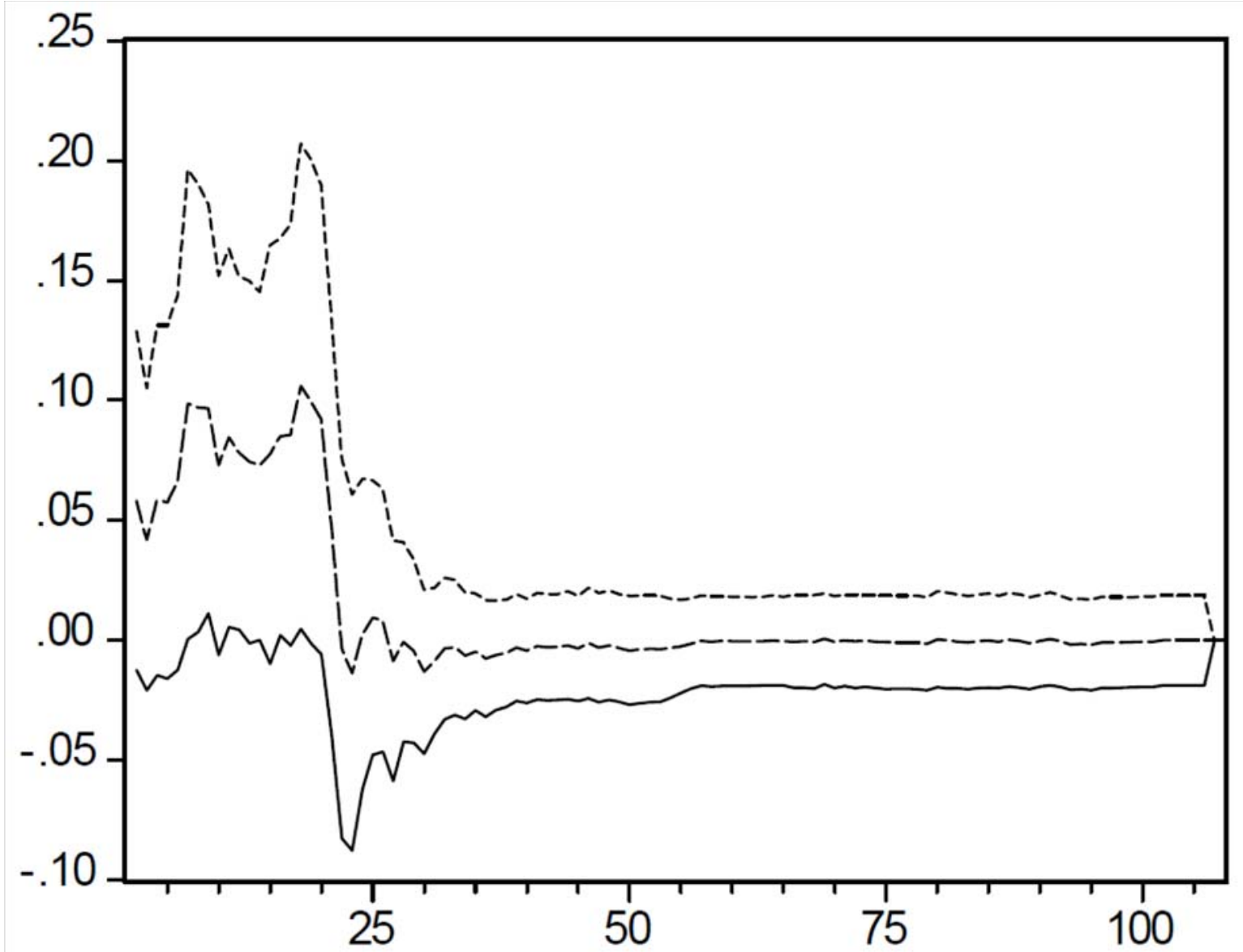

Figure 1. Increasing-sample estimates of $d$ (large-dash) \pm two standard error bands (small-dash for + and solid for - , respectively).

In order to test more rigorously for a structural break in the $d$ coefficient, we employ the Wald test proposed by Andrews (1993) for GMM estimators. This test is designed to find a structural change when the date of the change is unknown. The null hypothesis of the test is parameter stability, and is rejected for large values of the statistic. The statistic is constructed by splitting the sample into two parts, calculating the coefficients and the corresponding variances and then moving the threshold towards the end of the sample and repeating the exercise. A value of 
the statistic is found at each iteration; the test is a 'sup' test, so the date with the largest statistic is the date where it is most likely that the change occurred. Statistical significance can be judged using the critical values calculated by Andrews (1993). Figure 2 reports the Wald statistic for coefficient $d$, where we look for the break over the whole sample (excluding the first and last 47 observations). The statistic clearly suggests that there is a change in the coefficient around quarter 21, which added to the initial 47 observations leads to 1981:1 as the suggested break. The other high values of the statistic are obtained starting from around 1979. This is robust to searches performed over different samples, with different timing and duration of the interest rate. The break (as indicated by this test) is always inside the 1979-1982 period.

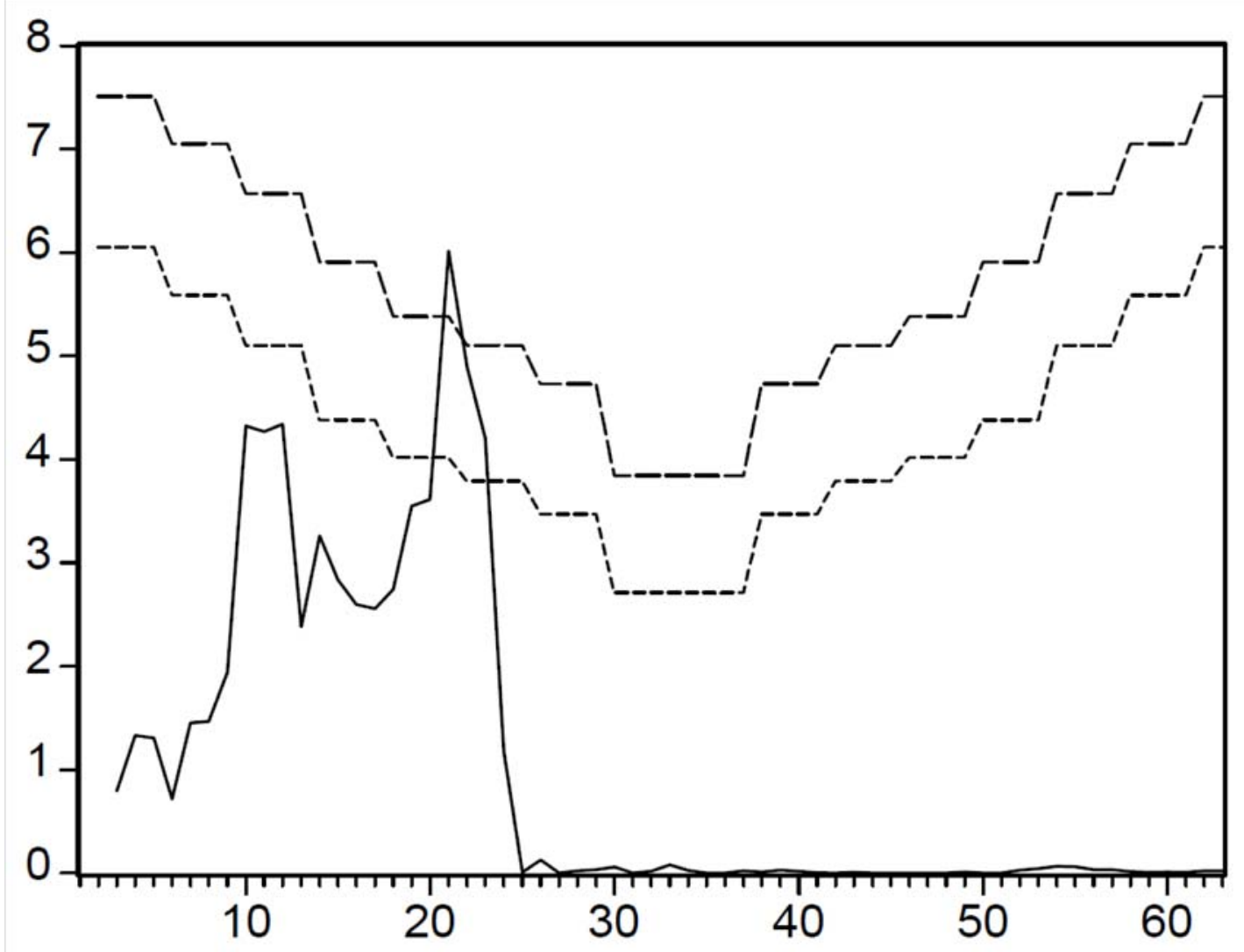

Figure 2: Andrews' Wald statistic for $d$ (solid line) and 5 and 10 percent critical values (large and small dash, respectively).

What can explain this evidence? In the following section, we introduce a model that can generate an AEIS without a restricted sign: indeed, the sign depends on the share of people participating in asset markets. We then present institutional evidence that the share of households participating in asset markets in the US has changed dramatically in the late 1970s -early 1980s. 


\section{Explaining the Empirical Evidence: Limited Asset Market Participation and the OEE.}

We briefly outline a theory that allows the derivation of the OEE under limited asset market participation (LAMP, for short) and can generate a change in the sign of the AEIS driven by changes in one parameter: the fraction of agents participating in asset markets. We model LAMP in a way that has become standard in the macroeconomic literature reviewed below. Namely, we assume that a fraction of agents have zero asset holdings, and hence do not smooth consumption but merely consume their current disposable income, while the rest of the agents hold all assets and smooth consumption. Models incorporating this insight have been recently used in the macroeconomic literature. First, some version of this assumption -whereby a fraction of agents does not hold physical capital- has been proposed by Mankiw (2000) and extended by Galí, Lopez-Salido and Valles (2007) for fiscal policy issues. ${ }^{18}$ Second, the monetary policy literature trying to capture the 'liquidity effect' assumes that asset markets are 'segmented', leading to a set up similar to ours. (e.g. Alvarez, Lucas and Weber, 2003). Finally, and most relatedly, two recent monetary policy studies by Galí et al. (2004) and Bilbiie (2008) have used this assumption and addressed issues of stability properties of interest rate rules, optimal monetary policy, and the relationship between monetary policy and macroeconomic performance.

This modelling choice is motivated both by direct data on asset holdings and by an extensive empirical literature studying consumption behavior. The latter seems to suggest that, regardless of whether aggregate time series or micro data are used, consumption tracks current income for a large fraction of the US population (Campbell and Mankiw, 1989 and Fuhrer, 2000). More recent studies using micro data also find that a significant fraction of the US population fails to behave as prescribed by the permanent income hypothesis (e.g. Hurst, 2006; Parker, 1999; Souleles, 1999 and Johnson et al., 2004). ${ }^{19}$ Finally, direct data on asset holdings shows that a low fraction of US population holds assets in various forms. ${ }^{20}$ In a general sense, this paper can be regarded as adding to this growing literature that points to the relevance of limited asset market participation to explain certain macroeconomic phenomena.

This paper's theoretical model is also related to an important contribution by Guvenen (2006), who studies a calibrated business cycle model with limited stock market participation and heterogeneity in individual elasticities of intertemporal substitution EIS. He shows that such model can explain capital and output fluctuations as long as most of the wealth is held by individuals with a high EIS, despite the majority of the population having a low EIS (and hence generating a low AEIS

\footnotetext{
${ }^{18}$ The latter paper argues that this modelling assumption can help explaining the effects of government spending shocks. See also Bilbiie and Straub (2004).

${ }^{19}$ Johnson et al. (2004) show that a large part of the US population consumed the unexpected increase in transitory income generated by the 2001 tax rebate and find that the response was higher for households with low wealth. Relatedly, Wolff and Caner (2002) use 1999 PSID data to find that 41.7 percent of the US population can be classified as asset-poor when home equity is excluded from net worth, whereas 25.9 percent are asset-poor based on net worth data.

${ }^{20}$ Vissing-Jorgensen (2003) reports based on the PSID data that of US population 21.75 percent hold stock and 31.40 percent hold bonds. Data from the 1989 Survey of Consumer Finances shows that 59 percent of US population had no interest-bearing financial assets, while 25 percent had no checking account either.
} 
when judged by data on consumption). Our model is similar in spirit to Guvenen's, since in his framework households who hold no stocks but hold bonds are also those households who do little intertemporal substitution due to preferences (have a low EIS). In our framework, failure to substitute intertemporally occurs (in equilibrium) because our non-asset holders are also excluded from the bond market. ${ }^{21}$ When trying to explain a change in the sign of the AEIS documented above, our model does not rely on structural changes in the preference structure, something that would be needed in Guvenen's framework in order to explain this evidence. Lastly, one fundamental difference between two frameworks is that there is no steady state in Guvenen (markets are incomplete); in our framework, markets are segmented and a steady state exists, which allows us to analyze the switch of the AEIS sign analytically. ${ }^{22}$

The exposition here is stripped down to the essential. We adopt a set of assumptions that make the model particularly tractable without affecting its essence: in particular, log utility and increasing returns to scale due to a fixed cost and inducing zero steady-state profits. We refer the interested reader to Bilbiie (2008) for a full-fledged theoretical analysis of this framework, and to our Appendix A for a model with habit formation that nests this simple version as a special case.

There are two types of households: asset holders indexed by $S$, trading statecontingent assets and shares in firms, consuming $C_{S, t}$ and working $N_{S, t}$ hours; and non-asset holders indexed by $H$, who do not participate in any of the asset markets and simply consume $C_{H, t}$ their current disposable income resulting from working $N_{H, t}$ hours at the market real wage $W_{t} \cdot{ }^{23}$ The shares of these agents in the total population are $1-\lambda$ and $\lambda$ respectively and are assumed to be constant. We focus on small fluctuations around a steady state and let lowercase letters denote percentage deviations of a variable from its steady-state value. Consumption of asset-holders obeys a standard Euler equation: $c_{S, t}=E_{t} c_{S, t+1}-\left[r_{t}-E_{t} \pi_{t+1}\right]$, where $r_{t}-E_{t} \pi_{t+1}$ is the real interest rate (since utility is logarithmic, the intertemporal elasticity of substitution in consumption is one).

In order to derive an aggregate Euler equation, or the OEE, we need to express consumption of asset holders as a function of total consumption and hence output. Total consumption is given by definition as $c_{t}=\lambda c_{H, t}+[1-\lambda] c_{S, t} \cdot{ }^{24}$ Under log utility, consumption of non-asset holders is equal to the real wage $c_{H, t}=w_{t}$ since their labor supply is fixed $n_{H, t}=0 .{ }^{25}$ Using asset holders' labor supply schedule $w_{t}=c_{S, t}+\varphi n_{S, t}$, where $\varphi$ is the inverse Frisch elasticity of labor supply, and the definition of total labor supply $n_{t}=[1-\lambda] n_{S, t}$, consumption of non-asset holders

\footnotetext{
${ }^{21}$ Indeed, if one set the EIS for non-stockholders to zero in Guvenen (2006), one would recover an asset market structure that is very similar to this paper's.

${ }^{22}$ We are grateful to an anonymous referee for pointing out this difference.

${ }^{23}$ In the background of non-participation in asset markets there could be many reasons (constraints or preferences); but as long as all reasons have the same observational consequence, their relative importance is immaterial for our purposes. Our preferred explanation consists of constraints such as transactions costs; recent theoretical and empirical research shows that such market frictions alone could account for the observed participation shares (see e.g. Vissing-Jorgensen, 2002 and He and Modest, 1995).

${ }^{24}$ This approximation only holds if steady-state consumption shares of the two types are equal, i.e. asset income is zero in steady-state. This will be insured by appropriate conditions on the production side.

${ }^{25}$ For log utility, income and substitution effects on labor are cancelled out. See Appendix A of Bilbiie (2007) for the case whereby labor supply of non-asset holders is also elastic.
} 
is $c_{H, t}=w_{t}=c_{S, t}+\varphi(1-\lambda)^{-1} n_{t}$. Substituted in the consumption definition, this implies: $c_{t}=\varphi \lambda(1-\lambda)^{-1} n_{t}+c_{S, t}$. We can further substitute hours worked by using the production function for final output $y_{t}=[1+\mu] n_{t}+[1+\mu] a_{t}$, where $\mu$ represents both the steady-state net mark-up and the degree of aggregate increasing returns to scale ${ }^{26}$ and $a_{t}$ is exogenous technology, and use the goods market clearing condition $c_{t}=y_{t}$ (aggregate expenditure consists of consumption only), to solve for consumption of asset-holders as:

$$
c_{S, t}=\delta y_{t}+(1+\mu)(1-\delta) a_{t}, \text { where } \delta \equiv 1-\varphi \frac{\lambda}{1-\lambda} \frac{1}{1+\mu} .
$$

Substituting (3.1) into the Euler equation of asset holders we find the OEE, or 'intertemporal IS curve':

$$
y_{t}=E_{t} y_{t+1}-\delta^{-1}\left[r_{t}-E_{t} \pi_{t+1}\right]+(1+\mu)\left(1-\delta^{-1}\right)\left[a_{t}-E_{t} a_{t+1}\right]
$$

Direct inspection of (3.2) suggests the non-linear impact that LAMP has on the AEIS $\delta^{-1}$. Specifically, there exists a threshold value of the share of non-asset holders beyond which the AEIS changes sign, which is given by: ${ }^{27}$

$$
\lambda^{*}=\frac{1}{1+\varphi /(1+\mu)} \text {. }
$$

For high enough participation rates $\lambda<\lambda^{*}, \delta$ is positive and we are in what we call the 'Standard Aggregate Demand Logic' region (SADL for short), whereby real interest rates restrain aggregate demand. As $\lambda$ increases towards $\lambda^{*}$, the sensitivity of aggregate demand to interest rates increases in absolute value, making policy more effective in containing demand. However, once $\lambda$ is above the threshold $\lambda^{*}$ we move to the 'Inverted Aggregate Demand Logic' region (IADL for short) where increases in real interest rates become expansionary. As $\lambda$ tends to its upper bound of $1, \delta^{-1}$ decreases towards zero, and monetary policy is ineffective as nobody holds assets. The IADL case occurs when enough agents consume their wage income $w_{t}$ ( $\lambda$ high) and/or wage is sensitive enough to real income $y_{t}$ ( $\varphi$ high). Calculations in Bilbiie (2008) show that for a range of $\varphi$ between 1 (unit elasticity) and 10 (0.1 elasticity) the threshold share of non-asset holders is lower than 0.5 to as low as around 0.1 respectively.

How can an increase in interest rates become expansionary when asset market participation is restricted enough? To answer this question, it is useful to conduct a simple mental experiment whereby the monetary authority engineers a one-time discretionary increase in the real interest rate $r_{t}-E_{t} \pi_{t+1}$. In the standard, fullparticipation economy, an increase in interest rates leads to a fall in aggregate demand today. Asset holders are also willing to work more at a given real wage (labor supply shifts rightward), but labor demand shifts left if prices are sticky (not all the fall in demand can be accommodated via cutting prices). The new equilibrium is one with lower output, consumption, hours and real wage. Suppose now that we are in an economy with limited participation, but $\lambda<\lambda^{*}$ either because participation is not restricted 'enough' or labor supply is not inelastic

\footnotetext{
${ }^{26}$ This insures that asset income is zero in steady-state, inducing equalization of steady-state consumption shares and hours, so that all algebra here is consistent.

${ }^{27}$ Note that the only way for $\delta$ to be independent of $\lambda$ is for $\varphi$ to be zero, i.e. labor supply of asset holders be infinitely elastic. In this case, consumption of all agents is independent of wealth, making the heterogeneity introduced in this paper irrelevant.
} 
enough. The fall in real wage brought about by the intertemporal substitution of asset holders now means a further fall in demand, since non-asset holders merely consume their wage income. This generates a further shift in labor demand, so the new equilibrium is one with even lower (compared to the full-participation one) output, consumption, hours and real wage.

This effect could at first sight seem monotonic over the whole domain of $\lambda$ : the more restricted asset market participation, the stronger the contractionary effect on demand and hence on labor demand, and hence the more effective monetary policy. In order to understand why this is not the case, it is helpful to consider the additional distributional dimension introduced by limited asset market participation. The further demand effect that occurs because of non-asset holders has an effect on profits: both marginal cost (wage) and sales (output and hours) fall. The relative size of these reductions (and the final effect on profits) depends on the relative mass of non-asset holders and on labor supply elasticity. In particular, if labor supply is inelastic enough and/if asset market participation is limited enough such that $\lambda>\lambda^{*}$, an increase in profits would occur that would generate a positive income effect on asset holders. ${ }^{28}$ This expansionary effect contradicts both the initial 'intertemporal substitution' effect on labor supply of asset holders and the contractionary effect of monetary policy on their demand. For equilibrium to be consistent with the initial incentives, labor demand has to shift rightward. The equilibrium is reached whereby the expansion in labor demand is high enough to generate an increase in real wage (that suffices to make non-asset-holders demand the extra output produced), and low enough not to generate a too strong fall in profits (that would instead imply a further reduction in demand from asset holders). This is an equilibrium whereby consumption, output, hours and the real wage increase - hence 'expansionary monetary contractions'.

3.1. The OEE with Habits. In this section we show how the introduction of habit formation into the limited asset markets participation model can give rise to an OEE of the form estimated in section 2 above. Reassuringly, we find that the AEIS can still switch sign for low enough degrees of limited participation, as our empirical results suggest.

The utility function is given by: $U_{j}\left(C_{j, t}, N_{j, t}\right)=\ln \left(C_{j, t}-\gamma C_{t-1}\right)-\theta N_{j, t}^{1+\varphi} /(1+\varphi)$. Leaving the rest of the economy unchanged, we obtain the following modified OEE, which is a theoretical counterpart to the estimated equation (see Appendix A for details and derivation):

$$
y_{t}=\frac{\Gamma_{1}}{\Gamma_{1}+\Gamma_{2}} E_{t} y_{t+1}+\frac{\Gamma_{2}}{\Gamma_{1}+\Gamma_{2}} y_{t-1}-\frac{1-\gamma}{\Gamma_{1}+\Gamma_{2}}\left[r_{t}-E_{t} \pi_{t+1}\right]+\varepsilon_{t},
$$

where

$$
\begin{aligned}
\Gamma_{1} & =1-\frac{\lambda}{1-\lambda} \frac{\varphi}{1+\mu}\left[1+\frac{\gamma \mu}{1+\varphi(1-\gamma)}\right] \\
\Gamma_{2} & =\gamma\left[1-\frac{\lambda}{1-\lambda} \frac{\varphi}{1+\varphi(1-\gamma)}\right]
\end{aligned}
$$

\footnotetext{
${ }^{28}$ Note that asset holders have in their portfolio $(1-\lambda)^{-1}$ shares: if total profits fell by one unit, dividend income of one asset holder would fall by $(1-\lambda)^{-1}>1$ units. In the standard model all agents hold assets, so this channel is completely irrelevant. Any increase in wage exactly compensates the decrease in dividends, since all output is consumed by asset holders.
} 
Note that for $\gamma=0$, this reduces to the economy without habits in the previous section since $\Gamma_{2}=0$ and $\Gamma_{1}=1-\frac{\lambda}{1-\lambda} \frac{\varphi}{1+\mu}=\delta$. If $\lambda=0$, this boils down to a standard economy with habits: $\Gamma_{1}=1, \Gamma_{2}=\gamma$. A negative AEIS occurs if and only if:

$$
\lambda>\frac{1+\gamma}{1+\gamma+\frac{\varphi}{1+\mu}\left(1+\frac{\gamma(1+2 \mu)}{1+\varphi(1-\gamma)}\right)}
$$

Numerical simulations for plausible parameter values suggest that the threshold $\lambda$ obtained under habits is largely invariant to the magnitude of $\gamma \cdot{ }^{29}$ Therefore, a change in asset market participation is consistent with the switch in the sign of the AEIS documented above for the case with habit persistence.

3.2. Relation to Campbell and Mankiw (1989). Campbell and Mankiw (1989), henceforth CM, estimate the share of 'rule-of-thumb' households by assuming that these households consume a constant fraction of total income, and that this fraction (denoted by $\lambda^{C M}$ ), is equal to the share of rule-of-thumb households in the population. ${ }^{30}$ Specifically, CM assume (where $\hat{c}_{H, t}$ and $\hat{y}_{H, t}$ denote average consumption and income per group):

$$
\hat{c}_{H, t}=\hat{y}_{H, t}=\lambda^{C M} y_{t}
$$

Together with the assumption that consumption of the optimizing agents follows permanent income ( $\hat{c}_{S, t}$ is consumption of this group), total consumption is given by:

$$
\begin{aligned}
c_{t} & =\lambda^{C M} y_{t}+\hat{c}_{S, t}, \text { or in differences: } \\
\Delta c_{t} & =\lambda^{C M} \Delta y_{t}+\Delta \hat{c}_{S, t}=k+\lambda^{C M} \Delta y_{t}+\epsilon_{t,}^{C M}
\end{aligned}
$$

where $\epsilon_{t}$ is the change in agents' assessment of total permanent income. This is the equation estimated by CM.

The difference between this approach and ours can be seen most clearly by comparing (3.5) with a similar expression derived in our framework: ${ }^{31}$

$$
c_{t}=\frac{\lambda}{1-\lambda} \frac{\varphi}{1+\mu} y_{t}+c_{S, t}-\frac{\lambda}{1-\lambda} \varphi a_{t} .
$$

The partial elasticity of consumption to total income is, in our case, a non-linear function of the share of non-asset holders, labor supply elasticity and the steadystate markup (degree of market power). Specifically, the two coincide if:

$$
\lambda^{C M}=\frac{\lambda}{1-\lambda} \frac{\varphi}{1+\mu} .
$$

However, as discussed above, the sensitivity of consumption to income can in our case be larger than one and induce a negative AEIS, whereas in CM it cannot. The fundamental difference $^{32}$ is that we assume that non-asset holders' income is made

\footnotetext{
${ }^{29}$ Results are available from the authors upon request.

${ }^{30}$ The same assumption is used by i.a. Fuhrer (2000), Gali et al (2007) and Canzoneri et al (2007).

${ }^{31}$ To derive this expression, one starts from the expression for total consumption derived in text: $c_{t}=\frac{\lambda}{1-\lambda} \varphi n_{t}+c_{S, t}$ and susbtitutes hours using the production function.

${ }^{32} \mathrm{~A}$ similar discussion applies to the comparison between our model with habits and the model with habits of Fuhrer (2000), who also estimates the share of rule of thumb consumers a la CM.
} 
only of labor income, whereas CM assume that it is equal to total income (and hence includes capital income also).

However, if one believes that rule-of-thumb behavior is related to non-participation in asset markets (and/or not holding physical capital), as e.g. in Mankiw (2000), Alvarez, Lucas and Weber (2001), Galí, Lopez-Salido and Valles $(2004,2007)$ and Bilbiie (2008), one cannot merely use the estimates of CM in order to parameterize the extent of limited asset markets participation: rule-of-thumb households do not receive any income other than labor income, since they do not hold any form of capital (be it physical or claims to profits). Therefore, their share of total income (and hence the elasticity of total consumption to total current income) becomes a non-linear, increasing function of: their share in population, the inverse of labor supply elasticity and of the share of profits (or the degree of increasing returns). It is then clear that macroeconomic models using a framework similar to ours but appealing to the CM estimate $\lambda^{C M}$ in order to 'calibrate' the parameter $\lambda$ are overestimating the share of rule-of-thumb households. For example, calibrating $\lambda$ using the Campbell-Mankiw estimate $\lambda^{C M}=0.5$, for standard values of net markup $\mu=0.2$ and inverse labor elasticity $\varphi=2$ delivers $\lambda=0.23$, i.e. less than half the original estimate. ${ }^{33}$

3.3. The OEE under Non-separable Preferences. In a recent paper, Basu and Kimball (2006) have argued that non-separability of consumption and leisure in the utility function has important implications for the estimation of the intertemporal elasticity of substitution. This section considers the same type of preferences used by Basu and Kimball (2006) and shows that: (i) they cannot deliver the change in the sign of the AEIS documented here and (ii) they imply an OEE that is very similar to the one derived under separable preferences. Intuitively, under non-separable preferences the growth of hours worked appears in the consumption Euler equation. However, as one uses a general equilibrium restriction (the resource constraint) to substitute consumption for output, one may equivalently use the production function to substitute hours for output and hence obtain an aggregate Euler equation that features only output. ${ }^{34}$

Specifically, we consider non-separable preferences consistent with balanced growth: $U\left(C_{t}, L_{t}\right)=\left\{\left[C_{t} h\left(1-N_{t}\right)\right]^{1-\sigma}-1\right\} /(1-\sigma)$, where $h($.$) is a function of$ leisure $1-N_{t}$, and $N_{t}$ are hours worked. In Appendix B, we show that the OEE becomes (if $h($.$) is the power function), abstracting from shocks:$

$$
y_{t}=E_{t} y_{t+1}-\delta^{-1}\left[r_{t}-E_{t} \pi_{t+1}\right] \text {, }
$$

${ }^{33}$ Finally, note that we can rewrite our equation (3.6) in difference form, using the Euler equation of asset holders to express the growth in their consumption as a function of real interest rates, as:

$$
\Delta c_{t}=\frac{\lambda}{1-\lambda} \frac{\varphi}{1+\mu} \Delta y_{t}+\left[r_{t}-E_{t} \pi_{t+1}\right]-\frac{\lambda}{1-\lambda} \varphi \Delta a_{t}
$$

Comparing this with the corresponding equation used by CM, one notices that in our framework the 'residual' $\epsilon_{t}^{C M}$ would naturally occur as a combination of real interest rates and (the first difference of) any exogenous shocks (in our example, technology).

${ }^{34}$ Note that this is not very different from what Basu and Kimball (2006) do; they do not estimate the coefficient on hours growth in the Euler equation, but use general equilibrium restrictions to parameterize it using the labor share in consumption expenditure from national income accounts. 
where

$$
\delta \equiv \frac{\sigma^{-1}}{1-\frac{\lambda}{1-\lambda} \frac{\eta}{1+\mu}+\frac{\sigma^{-1}-1}{(1+\mu)(1-\lambda)}},
$$

and $\eta=N /(1-N)$ is pinned down by steady-state hours worked. One can see immediately that under full participation $(\lambda=0), \delta$ is always positive: hence, the assumption of non-separable preferences cannot, by itself, generate the change in the sign of AEIS documented above. Moreover, Galí et al. (2007) have shown that the Euler equation obtained under non-separable preferences and full asset markets participation is inconsistent with evidence presented by Parker (1999), Souleles (1999), Johnson et al. (2004) and Galí et al. (2007) themselves, showing that temporary changes in lump-sum taxes have an effect of consumption. The evidence presented in the previous section suggests instead that failure by some agents to behave as prescribed by standard neoclassical theory is of empirical importance.

\section{Institutional Evidence for the Change in Asset Markets Participation}

In this section we put together some background institutional evidence suggesting that the U.S. economy in the mid 1960's and 1970s was characterized by lower asset market participation as compared to the post-1980 period. That is, we give economic substance to the econometric results presented above.

The change in asset markets participation is problematic to pin down: there is to our knowledge no empirical study documenting such a change, let alone that data availability problems abound. ${ }^{35}$ However, there is institutional information to support our view that financial markets changed fundamentally in the early 1980s, leading to more widespread asset holding. Mishkin (1991) and references quoted therein provide a comprehensive review of financial market developments in this period. For a variety of reasons having to do with excessive regulation, in the '70s asset holding was limited and most assets held by small savers were not making interest linked to market interest rates. In a nutshell, two restrictions were prevalent (i) limits on interest paid by commercial banks to allow S\&L to pay slightly more interest (Regulation Q), and no interest was being paid on checking accounts; (ii) discouragement of other financial market instruments - in 1970 Treasury was convinced to raise minimum denomination on T-bills to 10,000 USD, and bank holding companies and corporations not to issue small-denominated debt. Hence, small savers were not making the market interest rate, which was well recognized at least by Congress (and was to trigger a legislative response).

This situation changed in 1980, due both to legislators' response via deregulation and to markets' response via financial innovation, causes which are sometimes hard to disentangle. On the latter point, Wenninger (1984) and Silber (1983) list literally hundreds of instruments created by financial innovation, most of them gaining wide usage in the post-1980 period. ${ }^{36}$ On the former point, 1980 saw the

\footnotetext{
${ }^{35}$ Consumer Expenditure Survey data on asset holdings starts only in 1984, while the Survey of Consumer Finances over-samples high-wealth households (making it inappropriate for our exercise). The Panel Study of Income Dynamics (PSID) contains wealth data with a five-year frequency only starting in 1984. Some wealth information is contained in the family files previous to 1984 .

${ }^{36}$ Among them: a. consumer assets (saver certificates, money-market MM mutual funds, ceiling-free MM certificates, NOW and super-NOW accounts, MM deposit account); b. consumer credit and mortgages (equity access accoutns, secondary mortgage market, floating-rate loans,
} 
adoption of the Depository Institutions Deregulation and Monetary Control Act (DIDMCA). ${ }^{37}$ Among the most important provisions, the DIDMCA introduced a phaseout of Regulation Q, let Savings\&Loans Institutions make other types of loans and engage in other activities, approved many of the new instruments mentioned above nationwide, eliminated usury ceilings on mortgage loans and some business loans and provided uniform access to Fed reserve facilities for all depository institutions.

To give just an example (see Mishkin, 1991) of the magnitude of the change in financial markets: total assets of Money Market mutual funds increased from 4 billion in 1978 to 230 billion in 1982, and NOW accounts increased from 27 to 101 billion from 1980 to 1982. Moreover, the early 1980s saw the advent of Individual Retirement Accounts (IRAs), an important new saving vehicle. The introduction and spreading of new financial instruments and the elimination of ceilings on deposit rates (re-)linked saving decisions to market interest rates, which justifies our assumption about the change in asset market participation across the two periods.

This is further supported by evidence from the 1983 Survey of Consumer Finances data on asset holdings and net worth. Table 8 therein shows that from 1970 to 1983 the percentage of families holding certificates of deposit changed from 8 to 20, for money market accounts from 0 to 14 . Table 5 in the Second report shows that the percentage of families with net worth less than 10.000 USD fell from $56 \%$ to $38 \%$ (see Wolff and Caner (2002) for a careful study of asset-poverty dynamics using post-1984 PSID data). Finally, the New York Stock Exchange reports that the proportion of U.S. families holding shares has almost doubled over the period 1975-1985 (see NYSE,1986). Duca (2001) presents further evidence that the decline in transaction costs (e.g. mutual fund loads, brokerage fees, and cost of exchangetraded funds) led to more widespread asset holding since the early 1980s. Jones (2002) also shows -see his Fig. 3 and 4- that commissions and spreads for shares at the NYSE have declined abruptly in the late 1970s and early 1980s (e.g., one-way transaction costs declined from about 1.20 percentage points in the mid 70 s to 0.60 in the early 80s). Corroborated with the phasing out of Regulation Q such that savings account started actually making the market interest rate, all these arguments complete our justification for believing that the U.S. economy before 1980 was marked by relatively more limited asset markets participation.

\section{Conclusion}

Available estimates of the output Euler equation OEE consistently find insignificant values of the parameter governing the aggregate elasticity of intertemporal substitution AEIS (and hence the elasticity of aggregate demand to interest rates) $;^{38}$ as such, they pose a serious challenge to any macroeconomic model based

leasing and flexible credits, variable rate mortgages and consumption installment loans); c. Treasury securities (variable rate bonds, adjustable-rate Fannie MAE, etc.); d. Tax-exempt securities; e. corporate bonds (deep-discound bonds, zero coupon and variable-rate bonds, bonds with warrants and IR swaps); f. futures and options on cash market instruments, stock market indices, etc.

${ }^{37}$ Followed by the Garn-StGermain Act reinforcing such de-regulatory provisions.

${ }^{38}$ These findings are consistent with those of a related literature estimating Euler equations using consumption data briefly reviewed in the Introduction. 
on intertemporal substitution. Even if prices were sticky, in the absence of intertemporal substitution the monetary authority would have no leverage in influencing the economy. And even if taxation were distortionary, the fiscal authorities' choice of tax rates (for example on labor income) would leave the intertemporal allocation of labor unaffected.

In this paper we address this puzzle and propose an explanation based on three ingredients. Firstly, we argue that the zero AEIS over the whole post-1965 sample may be a convolution of elasticities with opposite signs over two subsamples, before and after the 'Great Deflation' period. We conduct structural break tests allowing for an endogenous breakpoint, and find the break date in the interval 1979-1982. While the AEIS estimated on post-1982 data is consistent with standard economic theory and intuition, the pre-1979 elasticity's 'wrong' sign poses a different challenge to macroeconomic models (since in a representative agent framework it would imply 'negative intertemporal substitution'). So secondly, we propose a model based on limited asset markets participation whereby the AEIS depends on the share of asset holders; we show that this model can generate the change in the sign of AEIS when the share of asset holders switches from a low to a high value. Furthermore, we show that our framework gives some interesting insights about the validity of estimates of the share of rule-of-thumb households in the economy based on income data as e.g. proposed. in Campbell and Mankiw (1989). Additionally, we show that our set up is compatible with a model with non-separable preferences as discussed in Basu and Kimball (2006), with the advantage of being able to deliver the estimated sign switch in the slope of the OEE. Finally, we review institutional evidence consistent with the discussed hypothesis, based on the tremendous amount of financial deregulation and innovation which led to more widespread participation in asset markets since the late 1970s and early 1980s.

This paper is a small part of a much larger picture. There is mounting evidence that other structural changes have happened in the US economy at the same time, most notably the end of the 'Great Inflation' period and the start of the Great Moderation (i.e. the fall in aggregate macroeconomic volatility). These changes are potentially related to changes in the stochastic distributions of shocks (Blinder, 1982) and in monetary policy conduct (Taylor, 1999 and Clarida, Gali and Gertler, 2000). Nevertheless, the evidence that we provide in this paper might help us understand the puzzle raised by existing estimates of the AEIS, by providing a possible structural interpretation of that puzzle. We explore this structural interpretation in related work (Bilbiie and Straub, 2011).

\section{References}

[1] Alvarez F., Lucas Jr., R. E., and W. Weber , 2001. "Interest Rates and Inflation," American Economic Review, 91(2), 219-225.

[2] Andrews, D., 1993 "Testing for Parameter Instability and Structural Change with Unknown Change Point" Econometrica, 61(4), 821-856

[3] Basu S., and M. Kimball, 2006, "Long-Run Labor Supply and the Elasticity of Intertemporal Substitution for Consumption", mimeo.

[4] Bilbiie, F.O. 2008, "Limited Asset Markets Participation, Monetary Policy and Inverted Aggregate Demand Logic", Journal of Economic Theory, 140(1), 162-196.

[5] Bilbiie, F.O. and R. Straub, 2004, "Fiscal Policy, Business Cycles and Labour Market Fluctuations," Working Paper 2004-6 at Magyar Nemzeti Bank.

[6] Bilbiie, F.O. and R. Straub, 2011, "Asset Market Participation, Monetary Policy Rules and the Great Inflation," Forthcoming, The Review of Economics and Statistics. 
[7] Blinder, A. S., 1982, "The Anatomy of Double Digit Inflation in the 1970s," in Inflation: Causes and Effects, edited by Robert E. Hall, 261-282. Chicago: University of Chicago Press.

[8] Brav, A. G. M. Constantinides and Christopher C. Geczy; 2002 "Asset Pricing with Heterogeneous Consumers and Limited Participation: Empirical Evidence." Journal of Political Economy, 110(4), pp. 793-824.

[9] Campbell, J. Y., 2003, "Consumption-Based Asset Pricing", Chapter 13 in George Constantinides, Milton Harris, and Rene Stulz eds. Handbook of the Economics of Finance Vol. IB, North-Holland, Amsterdam, 803-887, 2003

[10] Campbell, J. Y. and G.N. Mankiw, 1989, "Consumption, Income, and Interest Rates: Reinterpreting the Time Series Evidence," NBER Macro Annual 185-216.

[11] Canzoneri M., R. Cumby and B. Diba, "Euler Equations and Money Market Interest Rates: A challenge for monetary policy models ," Journal of Monetary Economics, 54(7), 1863 1881.

[12] Cargill, T. and G. Garcia, 1985, "Financial Reform in the 1980s", Stanford, California: Hoover Institution Press.

[13] Christiano, L. J., M. Eichenbaum and C. L. Evans, 2005, "Nominal Rigidities and the Dynamic Effects of a Shock to Monetary Policy", Journal of Political Economy, 113, 1-45.

[14] Clarida R., Galí J., and M. Gertler. 1999 "The Science of Monetary Policy: A New Keynesian Perspective," Journal of Economic Literature, 37(4), 1661-1707.

[15] Clarida, R., J. Galí, and M. Gertler 2000, "Monetary Policy Rules and Macroeconomic Stability: Evidence and Some Theory," Quarterly Journal of Economics 115, 147-180

[16] Duca, J. 2001, "The Democratization of America's Capital markets." Economic and Financial Review, Dallas Fed.

[17] Estrella A. and J. Fuhrer, 2002, "Dynamic Inconsistencies: Counterfactual Implications of a Class of Rational Expectations Models," American Economic Review, 92(4).

[18] Estrella A. and J. Fuhrer, 2003, "Monetary Policy Shifts and the Stability of Monetary Policy Models," The Review of Economics and Statistics, 85(1), 94-104.

[19] Fuhrer, J, 2000, "Habit Formation in Consumption and Its Implications for Monetary Policy, " American Economic Review, 90(3), 367-390.

[20] Fuhrer, J. and Olivei, G. 2005, "Estimating forward-looking Euler equations with GMM estimators: an optimal-instruments approach," Proceedings, Board of Governors of the Federal Reserve System (U.S.), 87-114.

[21] Fuhrer, J. and Rudebusch, G. 2004, "Estimating the Euler Equation for Output, Journal of Monetary Economics, 51, 1133-53.

[22] Galí, J., Lopez-Salido D. and J. Valles 2004, "Rule-of-Thumb Consumers and the Design of Interest Rate Rules," Journal of Money, Credit, and Banking, 36(4), 739-764.

[23] Galí, J., Lopez-Salido D. and J. Valles 2007, "Understanding the Effects of Government Spending on Consumption," Journal of the European Economic Association, 5(1), 227-270

[24] Galí, J. and Gertler, M., 1999, "Inflation Dynamics: A Structural Econometric Analysis, "Journal of Monetary Economics, 44(2), 195-222

[25] Guvenen, F., 2006. "Reconciling conflicting evidence on the elasticity of intertemporal substitution: A macroeconomic perspective," Journal of Monetary Economics, 53(7), 1451-1472

[26] Hall, R., 1988, "Intertemporal Substitution in Consumption," Journal of Political Economy, University of Chicago Press, 96(2), 339-57.

[27] Hansen L. and K. Singleton, 1996, "Efficient Estimation of Linear Asset Pricing Models with Moving Average Errors," Journal of Business and Economic Statistics, 14, 53-68.

[28] He, H. and D. Modest, 1995, "Market frictions and consumption-based asset pricing," Journal of Political Economy, 103, 94-117.

[29] Hurst, E. 2006, "Grasshoppers, Ants and Pre-Retirement Wealth: A Test of Permanent Income Consumers," NBER Working Paper 10098.

[30] Johnson, D, J. Parker, and N. Souleles, 2004, "Household Expenditure and the Income Tax Rebates of 2001," American Economic Review, 96(5), 1589-1610.

[31] Jones, C. 2002, "A Century of Stock Market Liquidity and Trading Costs", mimeo, Columbia Business School.

[32] King, R. G., Plosser, C. I. and S. T. Rebelo, 1988, "Production, Growth and Business Cycles I. The Basic Neoclassical Model". Journal of Monetary Economics 21, 195-232

[33] Mankiw, N. G. 2000, "The Savers-Spenders Theory of Fiscal Policy," American Economic Review, 90 (2), 120-125. 
[34] McCallum, B. and E. Nelson, 1998, "Performance of operational policy rules in an estimated semi-classical structural model," Proceedings, Federal Reserve Bank of San Francisco, issue Mar.

[35] Mishkin, F. S. 1991, "Financial Innovation and Current Trends in U.S. Financial Markets," NBER Reprints 1662 .

[36] New York Stock Exchange, 1986, "Shareownership 1985".

[37] Parker, J.A., 1999. "The Reaction of Household Consumption to Predictable Changes in Social Security Taxes," American Economic Review, 89(4), 959-973

[38] Peersman, G., and R. Straub, 2006, "Putting the New Keynesian Model to a Test", IMF Working Paper Series No. 06/135.

[39] Rotemberg, J. and M. Woodford, 1998, "Interest-Rate Rules in an Estimated Sticky Price Model," NBER Working Papers 6618, National Bureau of Economic Research, Inc.

[40] Sbordone, A., 2006, "U.S. Wage and Price Dynamics: A Limited Information Approach," International Journal of Central Banking 2 (3)

[41] Silber, W, 1983, "The Process of Financial Innovation," American Economic Review, 73(2), 89-95

[42] Smets, F. and R. Wouters, 2003, "An Estimated Stochastic Dynamic General Equilibrium Model of the Euro Area", Journal of the European Economic Association, 1, 1123-1175.

[43] Souleles, N., 1999, "The Response of Household Consumption to Income Tax Refunds, " American Economic Review, 89, 947-958.

[44] Taylor, J. B. 1999, "A Historical Analysis of Monetary Policy Rules," in Taylor, John B., ed., Monetary Policy Rules, Chicago: University of Chicago Press.

[45] Vissing-Jorgensen, A. 2002, "Limited Asset Market Participation and the Elasticity of Intertemporal Substitution", Journal of Political Economy, 2002, 10(4).

[46] Vissing-Jorgensen, A. 2003, "Perspectives on Behavioral Finance: Does "Irrationality" Disappear with Wealth? Evidence from Expectations and Actions," NBER Macroeconomics Annual 2003.

[47] Wenninger, J., 1984, "Financial Innovations in the U.S.,", BIS Economic Papers, 232-258

[48] Wolff, E. 2000, "Recent Trends in Wealth Ownership 1983-1997," Working Paper 300, The Levy Institute.

[49] Wolff, E. and Caner, A. 2002, "Asset Poverty in the United States, 1984-1999: Evidence from the Panel Study of Income Dynamics," Working Paper 356, The Levy Institute

[50] Woodford, M., 2003, "Interest and Prices: Foundations of a Theory of Monetary Policy ," Princeton University Press.

[51] Yogo Y., 2004, "Estimating the Elasticity of Intertemporal Substitution When Instruments Are Weak," The Review of Economic and Statistics, 86(3), 797-810.

\section{Appendix A. The OEE under LAMP and Habit Formation}

In this Appendix, we explore the implications of habit formation in consumption, which leads to an OEE featuring endogenous persistence, just as for the equation estimated in Section 2. Each type of consumer maximizes the present discounted value of the utility function: $U_{j}\left(C_{j, t}, N_{j, t}\right)=\ln \left(C_{j, t}-\gamma C_{t-1}\right)-\theta N_{j, t}^{1+\varphi} /(1+\varphi)$, subject to a budget constraint, which is given by, for each type respectively:

$$
\begin{aligned}
R_{t}^{-1} B_{S, t+1}+P_{t} C_{S, t} & =B_{S, t}+P_{t} D_{t}+W_{t} N_{S, t} \\
P_{t} C_{H, t} & =W_{t} N_{H, t},
\end{aligned}
$$

where $B_{S, t+1}$ is a portfolio of bonds carried in period $t+1$ and $D_{t}$ are real dividend payments on the portfolio of shares; the latter will be equal to $(1-\lambda)^{-1}$ times total 
monopoly profits. Optimality conditions are:

$$
\begin{aligned}
R_{t}^{-1} & =\beta E_{t}\left[\frac{P_{t+1}}{P_{t}} \frac{C_{S, t}-\gamma C_{t-1}}{C_{S, t+1}-\gamma C_{t}}\right] \\
\theta N_{S, t}^{\varphi} & =\frac{1}{C_{S, t}-\gamma C_{t-1}} \frac{W_{t}}{P_{t}} \\
\theta N_{H, t}^{\varphi} & =\frac{1}{C_{H, t}-\gamma C_{t-1}} \frac{W_{t}}{P_{t}}
\end{aligned}
$$

The rest of the economy is standard, see Bilbiie (2008) for details: monopolistically competitive firms produce the consumption goods at a marginal cost equal to the real wage in effective units and maximize profits. As a result, price is a markup over marginal cost: a constant markup, if prices are flexible, and a time-varying one, if prices are sticky. Equilibrium is obtained by imposing that all markets clear: the goods market, the labor market, and financial markets (which instead implies that bonds are in zero net supply and that each asset holder will hold $(1-\lambda)^{-1}$ shares and receive dividends on this portfolio).

We loglinearize all optimality conditions around a non-stochastic steady state, which is determined as follows. The Euler equation of asset holders implies $R \equiv$ $1+r=\beta^{-1}$. The marginal cost (the inverse of the gross markup) of a monopolistically competitive firm producing under linear technology subject to a fixed cost is $W N /[P(1+F / Y)]$ so the labor share is $W N / P Y=\left(1+\frac{F}{Y}\right) /(1+\mu)$ and the profit share $D / Y=\left(F_{Y}-\mu\right) /(1+\mu)$. Under the simplifying (but innocuous - see Bilbiie 2007) assumption that increasing returns due to fixed costs make profits be zero in steady state $F_{Y}-\mu$, we obtain that hours and consumption shares are the same for the two groups (in steady state only) $N_{H}=N_{S}=N$, $C_{H}=C_{S}=C=Y=W N$.

In order to derive the loglinearized OEE, we follow the same steps as those used for the economy without habits. The Euler equation of asset holders is:

$$
c_{S, t}-\gamma c_{t-1}=E_{t} c_{S, t+1}-\gamma c_{t}-(1-\gamma)\left[r_{t}-E_{t} \pi_{t+1}\right]
$$

The optimality conditions of non-asset holders in loglinearized form are $\varphi n_{H, t}=$ $w_{t}-(1-\gamma)^{-1}\left(c_{H, t}-\gamma c_{t-1}\right)$ and $c_{H, t}=w_{t}+n_{H, t}$. Combining the two, we obtain

$$
c_{H, t}=\left(1-\frac{\gamma}{1+\varphi(1-\gamma)}\right) w_{t}+\frac{\gamma}{1+\varphi(1-\gamma)} c_{t-1} \text {. }
$$

Using the labor supply schedule of asset holders $\varphi n_{S, t}=w_{t}-\frac{1}{1-\gamma}\left(c_{S, t}-\gamma c_{t-1}\right)$ and the same production function as in the case with no habits, as well as the goods market equilibrium condition $c_{t}=y_{t}$ we obtain:

$$
w_{t}=\left(\frac{\varphi}{1+\mu}+\frac{1}{1-\gamma}\right) y_{t}-\frac{\gamma}{1-\gamma} y_{t-1}
$$

Substituting this into the expression for $c_{H, t}$ found above, and the resulting expression into the definition of aggregate consumption, $c_{t}=\lambda c_{H, t}+(1-\lambda) c_{S, t}$, we obtain consumption of asset holders as a function of current and past aggregate output (consumption):

$$
c_{S, t}=\left[1-\frac{\lambda}{1-\lambda} \frac{\varphi}{1+\mu}\left(1+\frac{\gamma \mu}{1+\varphi(1-\gamma)}\right)\right] y_{t}+\frac{\lambda}{1-\lambda} \frac{\varphi \gamma}{1+\varphi(1-\gamma)} y_{t-1}
$$


The OEE as stated in text is obtained by substituting this in the Euler equation of asset holders.

\section{Appendix B. The OEE under Non-Separable Preferences}

In this Appendix we derive the aggregate OEE for the case of non-separable preferences consistent with balanced growth: $U\left(C_{t}, L_{t}\right)=\left\{\left[C_{t} h\left(1-N_{t}\right)\right]^{1-\sigma}-1\right\} /(1-\sigma)$, where $h($.$) OEE a function of leisure 1-N_{t}$, and $N_{t}$ are hours worked. To simplify algebra, we assume the functional form for $h():. h\left(1-N_{t}\right)=\left[1-N_{t}\right]^{\gamma}$. Note that since this in the class of preferences studied by King, Plosser and Rebelo (1988), labor supply of non-asset holders will still be inelastic just as in the separable case without habits. The loglinearized first-order condition for labor of asset holders OEE:

$$
\left(\frac{h^{\prime}}{h}-\frac{h^{\prime \prime}}{h^{\prime}}\right) N n_{S t}=w_{t}-c_{S, t}
$$

so the constant-consumption elasticity of labor supply will be the inverse of $\eta \equiv$ $\left(\frac{h^{\prime}}{h}-\frac{h^{\prime \prime}}{h^{\prime}}\right) N$; for the simple functional form, $\frac{h^{\prime}}{h}=\frac{\gamma}{1-N}$ and $\frac{h^{\prime \prime}}{h^{\prime}}=\frac{\gamma-1}{1-N}$, and so $\eta=\frac{N}{1-N}$ is pinned down by steady state hours worked and so:

$$
\frac{N}{1-N} n_{S t}=w_{t}-c_{S, t}
$$

The loglinearized Euler equation is:

$$
E_{t} c_{S, t+1}-c_{S, t}=\frac{1}{\sigma}\left[r_{t}-E_{t} \pi_{t+1}\right]-\frac{1-\sigma}{\sigma} \frac{h^{\prime} N}{h}\left[E_{t} n_{S, t+1}-n_{S, t}\right]
$$

where for the proposed functional form $\frac{h^{\prime} N}{h}=\gamma \frac{N}{1-N}=1$.Under full participation, this equation holds for aggregate consumption and hours worked: Basu and Kimball (2006) estimate it on aggregate data, exploiting that $h^{\prime} N / h$ will in equilibrium be equal to the labor share in consumption and parameterizing this to 0.8 . Under limited participation, we follow the same steps as in the main text to obtain $c_{S, t}$ as a function of total income/output $y_{t}$ :

$$
c_{S, t}=\left[1-\frac{\lambda}{1-\lambda} \frac{\eta}{1+\mu}\right] y_{t} \text {. }
$$

Substituting this and $n_{S, t}=[(1+\mu)(1-\lambda)]^{-1} y_{t}$ in the Euler equation, we obtain the aggregate Euler equation:

$$
y_{t}=E_{t} y_{t+1}-\delta^{-1}\left[r_{t}-E_{t} \pi_{t+1}\right],
$$

where

$$
\delta \equiv \frac{\sigma^{-1}}{1-\frac{\lambda}{1-\lambda} \frac{\eta}{1+\mu}+\frac{\sigma^{-1}-1}{(1+\mu)(1-\lambda)}}
$$

The condition for this object to become negative $\delta<0$ is:

$$
\lambda>\frac{\sigma^{-1}+\mu}{1+\eta+\mu} .
$$

With respect to the separable-utility case, two differences arise: i. $\eta$ is pinned down by steady state hours, so should be between 0.5 and 0.66 (implying a constantconsumption labor elasticity between 2 and 3); and ii. The presence of $\sigma^{-1}$ (which 
was 1 under separable preferences). Using the more general function $h($.$) , the$ condition can be shown to be:

$$
\lambda>\left(1+\frac{1+\eta-\sigma^{-1}}{1+\mu+\left(\sigma^{-1}-1\right)(\eta+\alpha)}\right)^{-1},
$$

where $\alpha \equiv \frac{h^{\prime \prime} N}{h^{\prime}}$, and $\eta+\alpha=\frac{h^{\prime} N}{h}>0$. 